Henning Nølke*

\title{
Semantics and Pragmatics of Bridge Language
}

\section{Introduction}

Dear Torben,

This is a transition day for you. You will have no more obligations, which of course won't prevent you from continuing your research activities that we have heard so much about today, but it will give you much more leisure time, hopefully, and hence more time to practise another of your favourite languages: the bridge language, a language which you master to near perfection. So I thought it would be appropriate, and almost symbolic, as the last speaker to talk about this particular language. As far as I know, it has never yet been the subject of linguistic analysis. I have also chosen this subject, because this language is rather often one that you and I employ together and - so I sincerely hope - we shall have even more opportunity to perfect our skills in bridge language in the future.

I shall try to show that the language of bridge has its own semantics and pragmatics which may be described by means of linguistic concepts and linguistic theory. First I shall outline the basic grammar of bridge, then I shall take a closer look at the language of bidding and, finally, I shall make some remarks on the language of playing.

\section{The basic grammar}

Bridge is a card game where two pairs play against each other. Each deal consists of two phases: a bidding sequence (called the auction) followed by the play of the cards. The aim of the bidding is to make a contract with the opponents, giving you the right to decide the trump suit and the obligation of taking a certain number of tricks. Each bid is a contract proposition naming a trump suit (or no trump) and a number of tricks. Each bid must be higher than the previous bid, which means that it should propose a higher ranking trump suit, more tricks or both. The ranking of the suits is clubs followed by diamonds, hearts, spades and no trump as the highest ranking 'suit'. If you cannot afford to make a higher bid you pass (no bid). The bidding goes on clockwise until three passes have followed each other closing the auction. The last bid before the three passes names the contract. The bidder who first proposed the agreed trump suit is called declarer and the other pair is called the defence.

During the auction the pairs use bidding boxes. A bidding box contains a number of cards, each naming a particular bid:

* Henning Nølke

Section for French

Department of Aesthetics \& Communication

Aarhus University

DK-8000 Aarhus C

nolke@hum.au.dk 


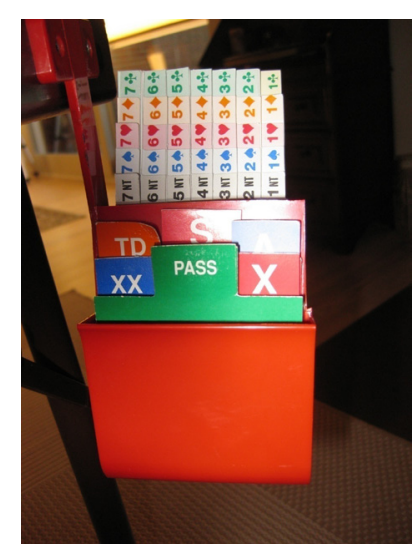

Figure 1. Bidding box

For each bid the player takes the corresponding card and places it in front of him/her as shown in figure 2:

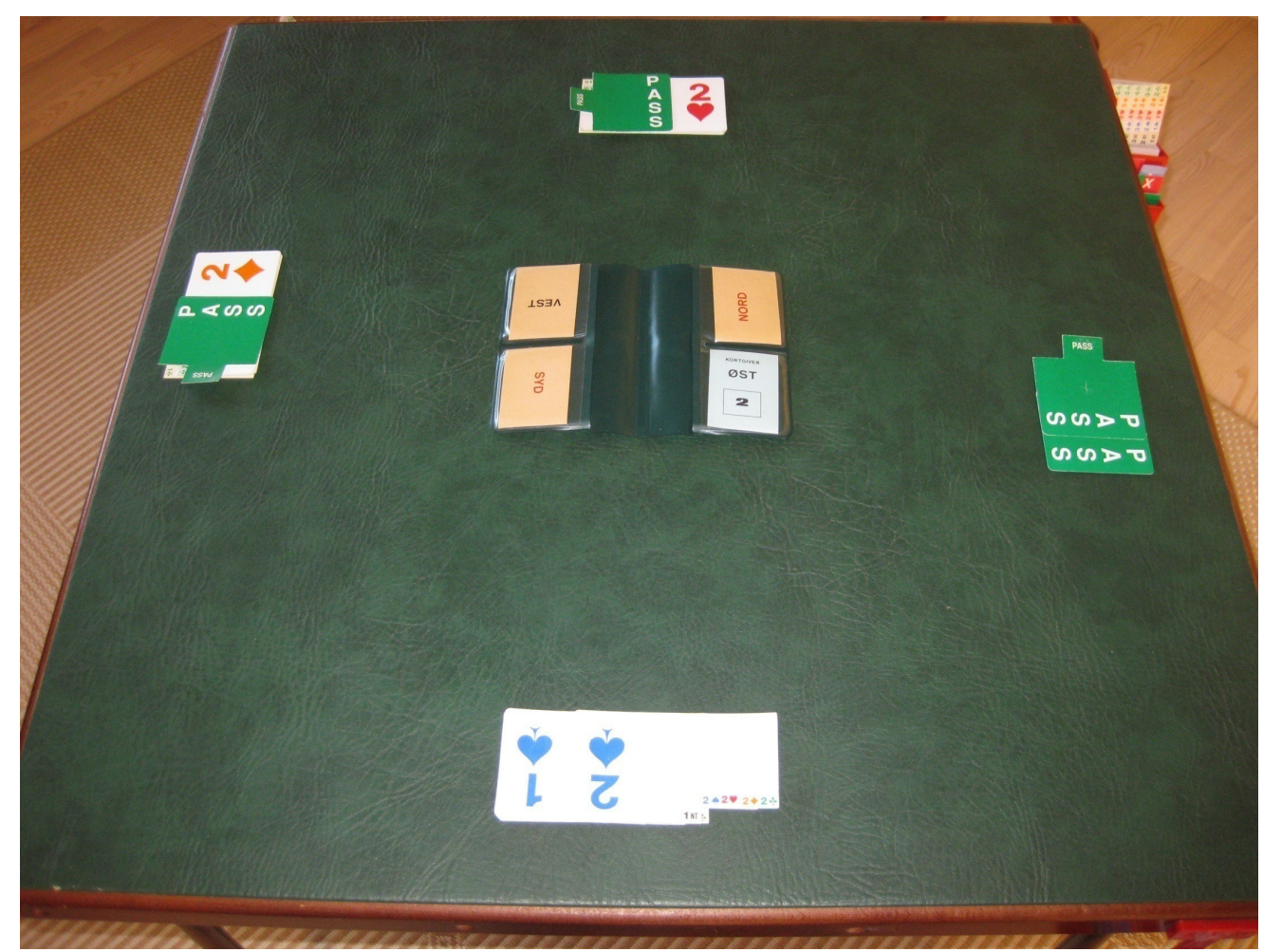

Figure 2. A bidding sequence

As shown in figure 2, the four player positions are named after the four points of the compass: North (NORD), East (ØST), South (SYD), West (VEST). In the auction illustrated, the player closest to the camera is East. (S)he has dealt the cards and opened the bidding with $1 \uparrow$, which means that (s)he proposes a contract of taking 7 tricks with spades as the trump suit. We see that the bids presuppose that the declarer makes more than six tricks. 14 is followed in turn by 2 $2 \boldsymbol{V}, \mathrm{P}$ (ass), $2 \boldsymbol{\uparrow}, \mathrm{P}, \mathrm{P}, \mathrm{P}$, the three passes ending the auction. The contract thus becomes $2 \boldsymbol{4}$. East becomes declarer and has contracted for eight tricks using spades as the trump suit. 
To start the play, the opponent to the left of the declarer (in casu South) makes the opening lead and the declarer's partner (called the dummy!) puts down his/her cards face up so that the declarer can administrate all the 26 cards of his/her side.

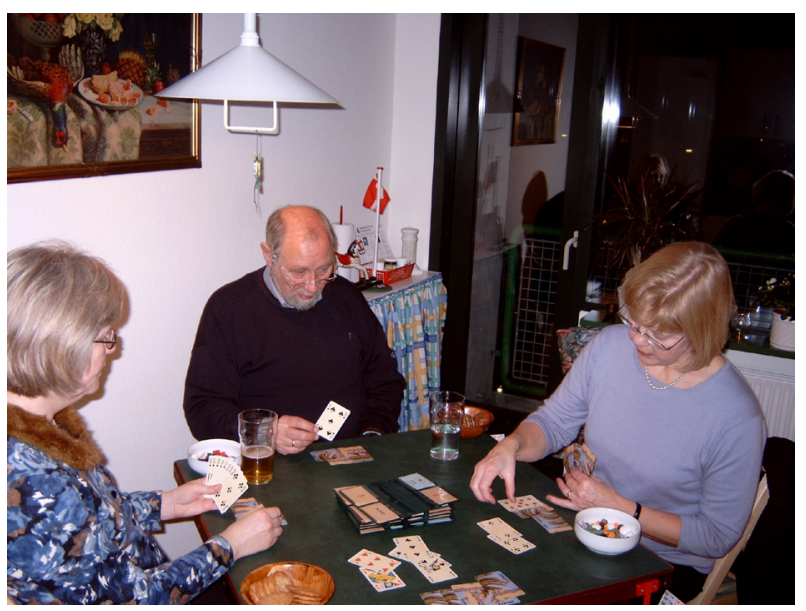

Figure 3. Torben as declarer

During the play of the cards, the opponents (the defence) normally use a signalling language (system). Bridge thus involves two languages:

- the bidding language

- the playing language

In this paper I shall concentrate on the bidding language, and only say a few words about the playing language.

\section{The language of bidding}

The syntax of the bidding language is quite simple. The dealer starts the bidding which then is a turn-taking system obeying simple rules. There is however one complication: Two more bids exist, namely double and redouble. Any bid by an opponent can be followed by a double (doubling the gain or loss), and any double by an opponent can be followed by a redouble (doubling the gain or loss of the doubled contact). I shall ignore these two bids in the following.

\subsection{Referential semantics and speech acts}

A bid is a speech act insofar as it consists of using a sign to perform a particular act. Each sign has a form and a normalized content whose denotation is a particular contract. Note however that only the final bid actually performs the act of making a contract. This means that all the previous bids in a sequence may be given a different content. This is exactly what happens when bridge players create bidding systems. A bidding system is a language in which each sequence of biddings embodies a particular complex meaning. Each bid is given a particular conventional meaning dependent on the context in which it is performed. In other words, the basic meaning of a bidding language is referential and descriptive. The main objective is to describe the hands as to their (playing) strength and their distribution or shape. Now, as Torben (Thrane 1980: 8) reminds us:

The basic principle of reference [is] that a great variety of linguistic forms may be used to refer to the same entity.

This is beyond any doubt true of natural languages. However, as the inventory of linguistic forms in bridge language is very restricted and as the number of possible referents, i.e. the possible hands, is very high (approximately $4 \times 10^{21}$ ), every single bid must be able to refer to many differ- 
ent hands. In practice, it refers to classes of hands. If we define the referential function just as in natural language:

$$
\begin{aligned}
& {[\ldots] \text { as a communicative function, or role, performed by a given linguistic expression of a specific }} \\
& \text { form, on a particular occasion for communicative purposes [...] (Thrane 1980: 43) }
\end{aligned}
$$

the referential function of a particular bid appears to be highly context-sensitive. We may here distinguish three types of context:

- The co-text

- The spatial context

- The situational context

\subsubsection{Co-text}

The referential function of a bid depends on the place the bid occupies in the bidding sequence. Let's take a simple example, the bid 1NT: If it is an opening bid (i.e. the first bid in the sequence), it normally refers to a rather strong hand evenly distributed, but if the same bid of $1 \mathrm{NT}$ is an answer to the partner's opening bid, as in the sequence ' $1 \checkmark \mathrm{P} 1 \mathrm{NT}$ ', in most systems it will show a weak, rather bad hand. If the opponents also intervene, the changes of referential function may be even more important.

\subsubsection{Spatial context}

The position at the table where the bidder is placed also plays a role. There are two relevant spatial dimensions:

- The position with respect to the first bidder. We talk about $1 \mathrm{st}, 2 \mathrm{nd}, 3 \mathrm{rd}$ and 4 th position. Thus an opening bid in 3 rd position will often refer to a weaker hand than an opening bid in 1 st or 2 nd position.

- The vulnerability. Players may be in vulnerable or not vulnerable position. This is basically a question of how much you may win or lose, but in most bidding language it has an influence on the meaning of some bids. Thus the opening bid $1 \mathrm{NT}$ is often stronger when vulnerable than when not vulnerable.

\subsubsection{Situational context}

The influence of the situational context is much more subtle. One aspect, however, is important. Some bids may change their meaning when the opponents use a particular system. This may be rather complicated, so I will not go into detail here.

\subsection{Conventional content}

In principle, there are two kinds of bids:

- Natural bids where there is some kind of natural relation between the form of the bid and its content, for instance a spade bid meaning that you have good spades or a double meaning that you do not think the opponents can make the proposed contract.

- Conventional bids where no such relation exists, for instance 1 meaning just that you are very strong without saying anything about your club holding.

Please note that according to the bridge laws, each pair must declare to their opponents what bidding (and playing) language they use before the play starts. There are more or less widespread bidding languages, but some pairs also create their own language. 
We see that the relation between form and content is not arbitrary but conventional, fixed by the special language used. There may however be some kind of natural relation between form and content as is the case with natural bids.

\subsection{Anaphors and cataphors}

In order to ensure longer bidding sequences giving better possibilities of exchanging information, some bids may have the additional meaning of being a forcing bid, which means that the partner must not pass as this would promote the bid to a bid for the final contract, with possible disastrous results. It goes without saying that a conventional bid tends to be forcing in order to avoid the risk of taking this bid in its basic natural meaning. Thus, if your 1 bid just shows a strong hand and says nothing about clubs, of course your partner must go on bidding.

The principle of forcing bids opens up for the use of anaphors and cataphors. In many sequences particular bids only get their exact referential function through an anaphoric relation to a previous bid. Of course it cannot be question of co-reference. One example could be the following sequence:

$$
2 * \mathrm{P} 2 \diamond \mathrm{P} ; 2 \bullet
$$

where $2 *$ only signals a very strong hand, $2 \checkmark$ is an automatic response (called a relay), and $2 \nabla$ then functions as an anaphor to the opening $2 *$ bid. 2 is strong because of the anaphoric relation, but it also brings its own meaning, namely that the strength is mainly constituted by a long and strong heart suit.

Cataphors may be rarer. An example of a cataphor could be a so-called advanced cue-bid, i.e. a bid which when made is ambiguous but is pointing to its own disambiguation to come in the following bid.

\subsection{Illocutionary acts}

We have seen that the final bid always performs the legal act of setting up a bilateral contract. All the other bids in a sequence, however, may perform other kinds of illocutionary acts. We may distinguish assertions, directives and interrogatives.

No doubt most bids are assertions trying to describe a hand by the referential function. Thus all natural bids are assertions. However, some languages have conventionalized some bids as directives or as interrogatives.

One convention that uses bids as directives is the so-called Jacoby convention. According to this convention, when the partner opens 1NT, the bids $2 \checkmark$ and $2 \checkmark$ command the partner to bid $2 \checkmark$ and $2 \uparrow$, respectively. There may be different reasons for doing so. This transfer bid may be made in order to stop with the strong hand (the opener) as declarer, but it may also serve as a first step for further investigation.

A convention that uses bids as interrogatives is the famous Blackwood convention, which uses the bid $4 \mathrm{NT}$ as a question for the number of aces held by the partner. Answers to interrogative bids are of course further examples of anaphors.

\subsection{Negotiation and competition}

The bidding is basically a negotiation with your partner and at the same time, it is a fight against the opponents. Negotiation and competition, so to speak, are two sides of the same coin and the bidding language should serve both purposes simultaneously. This means that exchange of information cannot be the only objective of the bidding. Since the opponents are listening in, it may be important not to be too informative or in some rare cases even to misinform. Do note, however, that this will also misinform your partner. 
In principle, the stronger side will be interested in exchanging as much information as possible. The longer the bidding sequence, the more details can be communicated, so the stronger side typically wants a long and undisturbed bidding sequence. And what is good for one side is bad for the other side, so the opponents would want to create as much disturbance as possible. However, bidding is always dangerous insofar as any positive bid may also be the last (and it may even be doubled) and thus be transformed into the contract. So risking a bid setting up a contract that could never be fulfilled is potentially dangerous.

Here we touch upon an aspect that we have not yet talked about: It might be cheaper (read better for the pair) not to fulfil their own contract than to let the opponents play theirs. It might thus be a good idea to try to 'buy' a contract, even knowing that it is unlikely to be fulfilled. This is called sacrificing. Keeping this in mind, especially the weak side can be interested in disturbing the opponents as much as possible by stealing their bidding space, thus leaving less room for meaningful negotiation.

The primary tool for disturbing is preemptive bidding. Making high bids may steal quite a lot of bidding space. Thus, if you open, say $4 \boldsymbol{A}$ in first position, you do not leave much room for the opponents. This is why most bidding languages define the meaning of the opening bid of 4 A as preemptive. However, in order to make it sensible, it should also have a reasonable referential function. It normally shows a hand with a very long spade suit and rather few high cards, the exact value depending on the spatial context, in particular on the vulnerability.

\subsection{Psychology and paralinguistic signs}

Finally, bridge language also involves psychological considerations. We may distinguish two main types: deliberate misinformation and interpretation of paralinguistic signs.

In some cases, it may be advantageous to deliberately misinform the three other players. Some ways of misinforming are:

- Underbidding: Hoping to get another opportunity, you may choose a lower bid showing a weaker hand than you actually have. Because you have then given a false picture of your hand, you might be doubled when you go on bidding, thus gaining more points.

- Overbidding (called boosting): The opposite could also be a good idea. Showing a stronger hand than you actually have could deter your opponents from doubling your contract which may turn out to be an excellent (advanced) sacrifice.

- Bluff: For instance by bidding spades as a natural bid without spades in your hand. This action may 'steal' the opponents' best suit, thus pushing them into an inferior contract. Bluffing, however, is a dangerous course of action, since your partner might completely overbid his hand if (s)he has good support for the suit you bid.

Note that it is strictly forbidden to agree with your partner in advance on the use of these psychological means. Therefore the partner must be misinformed just as much as the opponents, sometimes with disastrous results as a consequence.

Few players can avoid completely producing paralinguistic signs such as hesitation, the way of sitting at the table or of placing the bidding cards on the table. Of course, such signs should be made unconsciously. It is strictly forbidden to give extra information purposely in this way. It is indeed the case that such paralinguistic signs MUST not influence the partner's behaviour. His/ her acting should always be based exclusively on the information given by the auction. However, any player is allowed to try to interpret the opponent's paralinguistic signs, but any conclusion (s)he might draw is entirely at his/her own risk. 


\section{The language of playing}

When the play starts, the declarer administers all the 26 cards of his/her side, whereas the opponents cannot see their partner's cards (but of course the dummy's). This is why most players have developed special playing languages or discarding systems when defending.

Many of the same principles as we have discussed about bidding language also apply to playing language. This is due to the fact that both languages are subject to the same basic conditions: Players try to exchange information in a competitive context where the opponents listen and may disturb. Hence it is not surprising that we find the same main characteristics in playing language as in bidding language. Discard signals are basically referential and simultaneously produce speech acts. Thus some discard signals are assertions attempting to give the partner a picture of the shape of the hand; others are directives, inviting the partner to play a particular suit. Some signals only get their meaning through anaphoric and/or cataphoric relations and the meaning of some signals depends on the spatial context. I shall not go into details but restrict myself to giving some typical examples of signal types.

It is important to stress that just as what applies to bidding language, the meaning of all signals must have been declared to the opponents before starting, and the declarer is allowed to ask the discarder's partner for the established meaning of a particular discard when in turn.

First we distinguish leads and play ${ }^{1}$.

\subsection{Leads}

As we saw, the opponent to the left of the declarer makes the first lead which is called the opening lead. Consecutive leads are made by the player having won the previous trick. When making a lead, a defender tries to give a picture of his/her hand and in particular of the suit led. Two properties are essential: the strength (high card holding) and the length of the suit. Standard playing language involves the following lead signals:

- From a sequence of honour cards ${ }^{2}$, lead the highest. Thus the lead of a king, for example, shows the queen and normally also the knight. This lead gives no information as to the length of the suit.

- From an honour accompanied by a number of small cards, called spot cards ${ }^{3}$, lead a spot card to show the honour and, if possible, choose the fourth best in the suit to give the count of the suit at the same time. This lead aims at combining strength and length showing.

- From spot cards, lead one of the highest spot cards. The choice depends on the length. In this domain many competing signal systems exist. According to one of them, which is rather widespread, you should lead the higher from two cards and the second highest from three (or more, but avoid leading from longer spot card suits if possible!). From three cards you play the highest next time, thus showing that you started with exactly three cards.

These signals are used in opening leads. In some playing languages, slightly different rules apply to the following leads, but the main principles are normally retained.

\subsection{Play}

The defenders are able to provide each other with different kinds of information both when they follow suit and when they discard, being void in the suit played. In most playing languages, the general principles are the same as those that apply to leads: A small spot card signifies strength, a high spot card weakness and throwing an honour promises the following honour(s). Note, how-

1 Play here means contributing a card to a trick.

2 In most cases Ace, King, Queen, Knight and Ten are considered honour cards.

3 In most cases spot cards are cards smaller than the Ten. 
ever, that you sometimes have to play a particular card for technical reasons. Thus in third position it is normally best to play a high card in order to promote your partner's cards. This situation should not be confused with normal signalling situations.

Most playing languages combine these strength and weakness showing signals with signals showing distribution. Very often a small spot card promises an even number of cards and a high spot card an odd number. It goes without saying that combining strength and length signals may lead to complicated situations.

Most often these assertive signals essentially convert to directional ones. Thus the lead of a small spot card, showing strength, at the same time encourages the partner to return that suit when and if (s)he can, whereas the lead of a high spot card is to discourage him/her.

There is even more. In some particular situations an opponent can signal that (s)he wants his/ her partner to lead another particular suit. These signals are called suit preference signals. An example could be when your partner leads with an ace against a trump contract and you find a singleton in the dummy. In this case it is normally not a good idea to continue in the same suit. Then, if you throw a high card, you ask for the higher ranking of the two suits outside the trump suit, whereas a low card asks for the lower ranking.

These were only the most widespread playing language characteristics. Top players tend to develop much more refined playing languages. You should never forget, however, that no playing language can replace logical thinking. Thus an encouraging signal is by no means to be considered as an order but only as a piece of, hopefully helpful, advice.

Finally, opponents should never forget that the declarer will always be looking at these defensive signals, so some final pieces of advice could be:

- Only give honest signals when they are judged to be of more relevance to your partner than to the declarer (this is most often the case)!

- Give misleading signals when they cannot harm your partner's play!

- Silence may be golden!

\section{Conclusion}

Analyses of bridge language have just started. There is still no study of particular bridge languages or dialects and yet no diachronic studies have been made. There is so much more to say about bridge language, but I hope that my brief overview has shown that bridge language is in many aspects comparable to natural language. Just as natural language, it involves many different competences, and just as there are good and bad language users, there are good and bad bridge players. To be a good bridge player, you must acquire a thorough understanding of all these competences - as Torben has.

\section{References}

Francis, Henry/Francis, Dorothy/Truscott, Alan 2001: The Official Encyclopaedia of Bridge, $6^{\text {th }}$ edition. New York: ACBL.

Thrane, Torben 1980: Referential-semantic analysis. Aspects of a theory of linguistic reference. Cambridge/London/ New York: Cambridge University Press.

\section{Epilogue}

Dear Torben,

The Grammar of Bridge is still to be written. I would suggest that you and I write it together. This, of course, will require much empirical research $;$. Anyway, I hope we shall continue our bridge partnership, especially now that you hopefully will get more time for leisure activities. 
In Danish University jargon, the word fyrtårn, literally lighthouse or beacon of light, is used metaphorically about an outstanding researcher. You are a fyrtårn in linguistics, and you are also a great lover of good whisky. Your first talk at Aarhus School of Business was indeed about whisky. You explained to us that the appropriate answer to a question like 'What kind of whisky is that?' would be entirely dependent on the expectations one had as to the addressee's knowledge of whisky. In one case the answer 'That's a Scotch' would be perfectly informative, but talking to an expert, you should rather say: 'That's an Oban'. I hope you will find time, not only for writing the grammar of bridge, but also for tasting some good whisky.

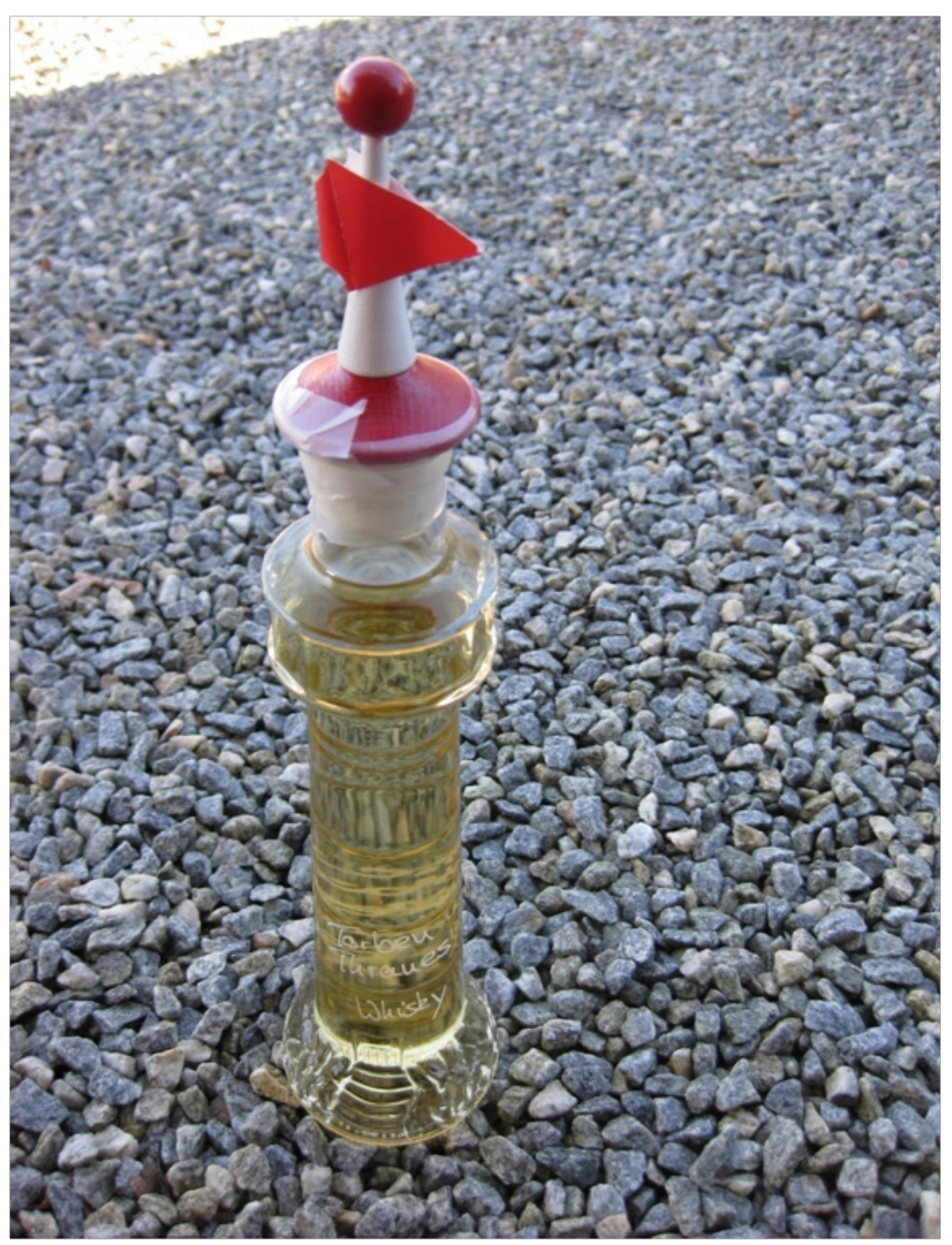

Figure 4. Torben's whisky 